\title{
Educação e pobreza: \\ limiares de um campo em (re)definição*
}

\author{
SILVIA CRISTINA YANNOULAS \\ Universidade de Brasília
}

SAMUEL GABRIEL ASSIS

Instituto Federal de Brasília

KALINE MONTEIRO FERREIRA

Universidade de Brasília

\section{INTRODUÇÃO}

Este artigo discute a produção acadêmica contemporânea brasileira sobre a relação entre educação formal e situação de pobreza. Para tanto, considera os artigos publicados em bases abertas controladas - como a Scientific Electronic Library OnLine (SciELO) e, complementariamente, o Google Acadêmico (Beta) -, e as dissertações e teses defendidas e incorporadas à Biblioteca Digital Brasileira de Teses e Dissertações (BDTD).

$\mathrm{Na}$ análise da documentação selecionada, entendeu-se que os programas de mestrado e doutorado constituem importante espaço de produção de conhe-

* A elaboração do presente artigo contou com o apoio da Coordenação de Aperfeiçoamento de Pessoal de Nível Superior (CAPES), entidade do governo brasileiro voltada para a formação de recursos humanos, através do Programa Observatório da Educação (Edital 038/2010 - CAPES/Instituto Nacional de Estudos e Pesquisa - INEP). Também agradecemos à Fundação de Empreendimentos Científicos e Tecnológicos (FINATEC) (Edital 2/2009) e ao Programa de Iniciação Científica (PROIC) do Decanato de Pesquisa e Pós-Graduação/Universidade de Brasília (DPP/UnB) (períodos 2009-2010) pelo apoio inicial à pesquisa aqui relatada. 
cimento, pois a pesquisa científica assume um lugar privilegiado na sua origem e estruturação. Em contrapartida, as revistas incluídas na seleção analisada pertencem majoritariamente aos próprios programas de pós-graduação em educação e envolvem procedimentos de controle de qualidade do conhecimento por elas difundido.

Os objetivos desta pesquisa são: 1) Propiciar um levantamento (localização e sistematização) da produção científica elaborada no contexto das ciências sociais e humanas sobre a relação entre situação de pobreza e educação formal, considerando as produções publicadas em bases on-line no período compreendido entre $1999 \mathrm{e}$ 2009; 2) Estabelecer uma tipologia (comparação e diferenciação) sobre como os pesquisadores e pesquisadoras interpretam essa relação; e 3) Analisar as questões de gênero, raça/cor e classe social (identificação e consideração) envolvidas na relação entre situação de pobreza e educação formal nessa produção científica.

A expectativa inicial do projeto foi a de que seus resultados facilitassem a definição de prioridades de pesquisa, apontassem lacunas ou áreas pouco exploradas e fortalecessem o estudo dessa temática pela academia brasileira. A relação entre situação de pobreza e educação formal é cara ao Grupo de Pesquisa Trabalho, Educação e Discriminação (TEDis), da Universidade de Brasília (UnB), pela sua inserção institucional no Departamento de Serviço Social e por sua preocupação com os aspectos educacionais da política social. Assim, faz parte dos esforços teóricos a tessitura de elos entre educação e serviço social.

\section{OS ACHADOS DA PESQUISA: ARTIGOS PUBLICADOS EM PERIÓDICOS CIENTÍFICOS}

Utilizando como localizadores os vocábulos "educação" e "pobreza”, foram identificados um total de 70 artigos nas bases abertas controladas, a saber, SciELO e Google Acadêmico (Beta); porém, foram considerados para análise apenas 36 deles.

Numa primeira triagem, alguns artigos foram descartados por não se enquadrarem no escopo da pesquisa (língua estrangeira, apresentar data de publicação anterior ao período pesquisado, reiteração nas bases consultadas, formato de entrevista ou resenha). Numa segunda triagem, foram descartados artigos que não contemplavam a temática principal da pesquisa (a relação entre educação formal e situação de pobreza), sendo que apenas citavam a palavra "pobreza", ou apenas referiam a "educação" como área de investimento, ou não estabeleciam uma clara relação entre o fenômeno educacional e a situação de pobreza.

\section{OS ACHADOS DA PESQUISA: DISSERTAÇÕES E TESES APROVADAS}

Como localizadores para realizar a procura na BDTD, também foram utilizados os vocábulos "educação" " "pobreza". Assim, a base de dados BDTD/Instituto Brasileiro de Informação em Ciência e Tecnologia (IBICT) apresentou 155 teses 
e dissertações que têm alguma vinculação aos temas pobreza e/ou educação, sendo selecionadas para análise 33 produções: 11 teses e 22 dissertações.

Primeiro foram eliminadas as dissertações e teses aprovadas fora do período considerado pela pesquisa. Em seguida, foi realizado um processo de seleção visando catalogar apenas aquelas produções que realmente se associavam ao tema da pesquisa (a relação entre educação formal e situação de pobreza) e descartando aquelas que apenas mencionavam a relação.

A seleção foi realizada da seguinte forma: primeiro, lia-se o resumo da tese ou da dissertação e também se observavam as palavras-chave, a fim de encontrar variáveis associadas à pesquisa. Depois, lia-se o sumário com a finalidade de encontrar questões trabalhadas nas teses ou nas dissertações que pudessem estabelecer alguma relação direta com o tema da pesquisa. Quando se encontrava em algum enunciado um tópico relacionado ao tema da pesquisa, era realizada a leitura integral do capítulo. Por fim, se não se encontrava nenhuma variável de pesquisa com os métodos anteriormente apresentados, lia-se a conclusão para verificar se de fato a tese ou a dissertação encontrada não estabelecia, mesmo que apenas superficialmente, uma relação entre educação formal e situação de pobreza.

\section{OS ACHADOS DA PESQUISA: AUTORES E SEUS GRUPOS DE PESQUISA}

Foi realizada uma busca na Plataforma Lattes e no Diretório de Grupos de Pesquisa do Conselho Nacional de Desenvolvimento Científico e Tecnológico (CNPq). Foram recuperados os currículos Lattes correspondentes a 98 autores. $\mathrm{Na}$ ocorrência de um mesmo autor para várias produções, este foi contabilizado apenas uma vez.

Também foram localizados e analisados dados de 55 grupos de pesquisa nos quais esses autores estavam predominantemente engajados para realizar suas pesquisas. Em casos de dedicação de um mesmo autor a dois ou mais grupos de pesquisa, considerou-se apenas o grupo no qual o pesquisador desempenhava um caráter de líder ou, não sendo líder, aquele grupo no qual se inscrevia a produção selecionada. O propósito dessa etapa foi mapear cartograficamente o campo: onde estão os pesquisadores e as pesquisadoras da relação entre situação de pobreza e educação formal?

\section{REFLEXÕES INICIAIS}

As produções selecionadas (artigos, dissertações e teses) são dispersas nos primeiros anos do período considerado, mas apresentam uma gradativa concentração, com ápice nos anos de 2007 e 2008 (28 produções) - conforme apresentado no Quadro 1. Essa concentração no final do período considerado indicaria um aumento em números superiores relativamente recente no interesse sobre o tema. O crescimento também pode ser explicado pela expansão e consolidação dos pro- 
gramas de pós-graduação em ciências sociais e humanas na última década, pois a maioria das produções selecionadas mantém algum vínculo com esses programas. No entanto, o declínio em 2009 pode estar fundamentado no fato de não estarem ainda disponíveis on-line as publicações e outros no momento da realização do trabalho de campo.

\section{Quadro 1 - Quantidade de produções por ano}

\begin{tabular}{|c|c|c|c|c|}
\hline \multicolumn{5}{|c|}{ Quantidade de produções (artigos, dissertaç̃es e teses) por ano } \\
\hline Ano & Artigos & Dissertações & Teses & Total \\
\hline 1999 & 1 & 1 & - & 2 \\
\hline 2000 & - & 1 & - & $\mathbf{1}$ \\
\hline 2001 & 4 & 1 & - & 5 \\
\hline 2002 & 3 & - & - & 3 \\
\hline 2003 & 4 & 1 & 1 & 6 \\
\hline 2004 & 1 & 3 & 1 & 5 \\
\hline 2005 & 3 & 2 & 1 & 6 \\
\hline 2006 & 1 & 6 & 1 & 8 \\
\hline 2007 & 8 & 5 & 3 & $\mathbf{1 6}$ \\
\hline 2008 & 8 & 2 & 2 & $\mathbf{1 2}$ \\
\hline 2009 & 3 & - & 2 & 5 \\
\hline Total & 36 & $\mathbf{2 2}$ & $\mathbf{1 1}$ & $\mathbf{6 9}$ \\
\hline
\end{tabular}

Fonte: Base de dados on-line SciELO, BDTDD, Google acadêmico (1999-2009).

Elaboração dos autores.

A produção bibliográfica sobre educação formal e situação de pobreza no período 1999-2009 é, em larga medida, uma atividade da região Sudeste do Brasil (32 artigos dos 36 selecionados; e 20 revistas das 24 produções que foram publicadas). Não houve nenhuma publicação de artigo ou aprovação de trabalho final de pós-graduação da região Norte ou Nordeste do Brasil. A realização desigual na produção do conhecimento sobre a temática é mais um indicativo da irregular distribuição dos incentivos à pesquisa e ao desenvolvimento da pós-graduação no país. ${ }^{1}$ Mas também pode refletir uma preocupação da região Sudeste, mais urbanizada, com as experiências de exclusão/inclusão de setores populares nas instituições tipicamente urbanas como a escola.

1 Santos e Azevedo (2009) analisam a situação dos programas de pós-graduação em educação no Brasil, sendo educação a área com maior produção sobre a relação entre a educação formal e a situação de pobreza. Em 2008, segundo as autoras, havia 89 programas de pós-graduação em educação, dos quais apenas 11 estavam localizados na região Nordeste. 
Quadro 2 - Quantidade de artigos publicados por região administrativa

\begin{tabular}{|c|c|}
\hline Publicação em revistas & Artigos \\
\hline Região Norte * & 0 \\
\hline Região Nordeste ${ }^{* *}$ & 0 \\
\hline $\begin{array}{l}\text { Região Centro-Oeste } \\
\text { Subtotal }\end{array}$ & \\
\hline 1. Revista de Economia e Sociologia Rural - DF & 1 \\
\hline \begin{tabular}{|l|} 
Região Sul \\
Subtotal \\
\end{tabular} & \\
\hline 1. Revista de Sociologia e Politica - PR & 1 \\
\hline 2. Revista Estudos Feministas - SC & 1 \\
\hline 3. Revista Katálysis - SC & 1 \\
\hline \begin{tabular}{|l|} 
Região Sudeste \\
Subtotal
\end{tabular} & \\
\hline 1. Paidéia-SP & 2 \\
\hline 2.Pró-Posiçôes - SP & 2 \\
\hline 3. Revista Acta Paulista de Enfermagem - SP & 1 \\
\hline 4. Revista Brasileira de Ciências Sociais - SP & 1 \\
\hline 5. Revista Brasileira de Educação - RJ & 3 \\
\hline 6. Revista Brasileira de Educação Médica - RJ & 1 \\
\hline 7. Revista Cadernos de Pesquisa-SP & 2 \\
\hline 8. Revista Cadernos de Saúde Pública-RJ & 2 \\
\hline 9. Revista Ciência É Saúde Coletiva - RJ & 3 \\
\hline 10. Revista Dados - RJ & 2 \\
\hline 11. Lua Nova: Revista de Cultura e Politica-SP & 1 \\
\hline 12. Revista de Saúde Pública-SP1 & 1 \\
\hline 13. Revista Educação Ẽ Sociedade - SP & 3 \\
\hline 14. Revista Educação e Pesquisa - SP & 1 \\
\hline 15. Revista Estudos Econômicos - SP & 1 \\
\hline 16. Revista Internacional de Direitos Humanos - SP & 1 \\
\hline 17. Revista Nova Economia - MG & 2 \\
\hline 18. Revista Psicologia E' Sociedade - MG & 1 \\
\hline 19. Revista Teias - RJ & 1 \\
\hline 20. Revista Tempo Social-SP & 1 \\
\hline Total de revistas & Total de artigos \\
\hline
\end{tabular}

Fonte: Base de dados on-line SciELO, BDTDD, Google acadêmico (1999-2009).

Elaboração dos autores.

* Não houve publicação de trabalho.

** Não houve publicação de trabalho.

O grau de dispersão em relação às revistas em que foram publicados os artigos selecionados é grande, podendo-se registrar no máximo três artigos numa mesma publicação, o que indica falta de especialização de um veículo científico na temática em questão. A maioria dos artigos publicados concentra-se em revistas situadas predominantemente na região Sudeste. 
A indicação de dispersão em relação às universidade onde foram aprovadas as teses e dissertações selecionadas também é grande, podendo-se registrar apenas alguns casos com quatro ou três trabalhos numa mesma instituição. Esse dado confirma a questão apontada anteriormente quanto à falta de especialização ou de consolidação da temática como campo de reflexão específico de uma determinada instituição.

Quadro 3 - Teses e dissertações aprovadas por região administrativa

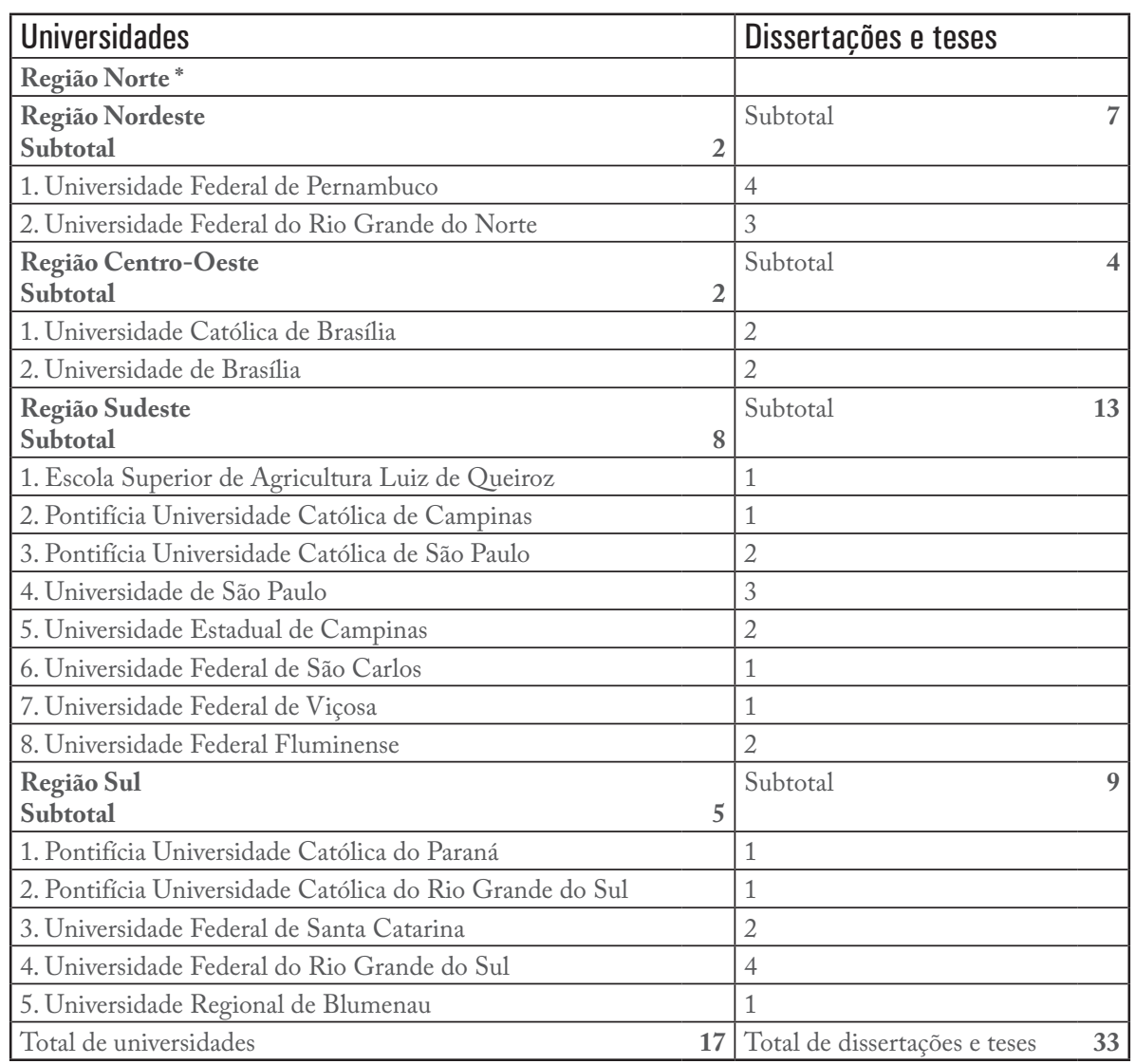

Fonte: Base de dados on-line SciELO, BDTDD, Google acadêmico (1999-2009).

Elaboração dos autores.

* Não houve aprovação de trabalho.

O Quadro 3 confirma a já apontada concentração de trabalhos na região Sudeste (8 das 17 universidades incluídas na seleção, e 13 das 33 produções consideradas nesta pesquisa). Entretanto, é necessário destacar que apenas a região Norte não aprovou dissertação ou tese alguma no período, o que não é surpreendente se se considerar esse número de aprovações para a região, pois os programas de pós-graduação são poucos e têm uma curta existência. Também é necessário ressaltar que a região Sul teve uma presença expressiva quanto ao número de teses/ dissertações e programas registrados (5 programas, com 9 produções). 
No âmbito da relação entre as produções e a área de conhecimento (tanto das revistas em que foram publicados os trabalhos como dos programas em que estes foram aprovados), encontrou-se uma concentração nas áreas de ciências sociais e humanas, com ênfase especial na área educacional. Outras áreas disciplinares com significativa incidência foram economia e serviço social.

\section{Quadro 4 - Produções por áreas de conhecimento}

\begin{tabular}{|l|c|c|c|c|}
\hline $\begin{array}{l}\text { Área de } \\
\text { conhecimento }\end{array}$ & $\begin{array}{c}\text { Número de } \\
\text { artigos }\end{array}$ & $\begin{array}{c}\text { Número de } \\
\text { dissertações }\end{array}$ & $\begin{array}{c}\text { Número de } \\
\text { teses }\end{array}$ & $\begin{array}{c}\text { Total de produções } \\
\text { em cada área }\end{array}$ \\
\hline Administração & - & 1 & - & $\mathbf{1}$ \\
\hline Ciência política & 2 & - & - & $\mathbf{1}$ \\
\hline Direitos humanos & 1 & - & - & $\mathbf{1 5}$ \\
\hline Economia & 6 & 8 & 1 & $\mathbf{2 9}$ \\
\hline Educação & 11 & 9 & 9 & $\mathbf{1}$ \\
\hline História & - & 1 & - & $\mathbf{5}$ \\
\hline Psicologia & 1 & 2 & - & $\mathbf{1 1}$ \\
\hline Saúde & 5 & - & - & $\mathbf{1}$ \\
\hline Serviço social & 9 & 1 & 1 & $\mathbf{6 9}$ \\
\hline Sociologia & 1 & - & - & $\mathbf{1 1}$ \\
\hline Total & $\mathbf{3 6}$ & $\mathbf{2 2}$ & & \\
\hline
\end{tabular}

Fonte: Base de dados on-line SciELO, BDTDD, Google acadêmico (1999-2009).

Elaboração dos autores.

Essa informação pode ser confrontada com as áreas disciplinares dos pesquisadores e seus grupos de pesquisa, para se verificar a consistência das afirmações anteriores. Assim, temos o Quadro 5, que contém os dados referentes aos 98 autores e aos 55 grupos de pesquisa nos quais desenvolvem suas atividades.

\section{Quadro 5 - Áreas de conhecimento dos pesquisadores/ autores e seus grupos de pesquisa}

\begin{tabular}{|l|c|c|}
\hline Área de conhecimento & Pesquisadores/autores & Grupos de pesquisa \\
\hline Administração & 1 & - \\
\hline Ciência política & 2 & 1 \\
\hline Direitos humanos & 1 & - \\
\hline Economia & 17 & 7 \\
\hline Educação & 33 & 21 \\
\hline História & 1 & 1 \\
\hline Psicologia & 5 & 16 \\
\hline Saúde & 20 & 9 \\
\hline Serviço social & 17 & - \\
\hline Sociologia & 1 & $\mathbf{5 5}$ \\
\hline Total & $\mathbf{9 8}$ & \\
\hline
\end{tabular}

Fonte: Base de dados on-line SciELO, BDTDD, Google acadêmico (1999-2009).

Elaboração dos autores. 
Analisando os 55 grupos de pesquisa e os 98 currículos Lattes dos autores em relação às áreas disciplinares, confirma-se o referido quanto às áreas economia, educação e serviço social. Mas também se observa uma quantidade expressiva de pesquisadores da saúde - muitos destes com produções científicas associadas ao tema do cuidado infantil-, porém, as linhas de pesquisa não enfocam a questão da educação ou da pobreza como um dos temas que se associa à atuação como pesquisador. Outra questão importante para se destacar é que a totalidade dos artigos da área de saúde contempla dois ou mais autores, sendo essa uma característica que apenas se apresenta nessa área disciplinar. Também se evidenciaram pesquisadores na área da economia cujas linhas de pesquisa tendem a estar mais direcionadas à avaliação dos programas de transferência de renda, tendo-se um enfoque maior nos temas da situação de pobreza e inclusão social, sendo que a educação aparece de modo mais superficial, como variável positivamente relacionada ao nível de renda. A maioria dos pesquisadores cujas linhas de pesquisa realmente enfocam o tema da educação formal e situação de pobreza tem formação e atua na própria área da educação.

Foram identificados 55 grupos de pesquisa com os quais os 98 pesquisadores estavam associados - seja como líder ou como pesquisador/colaborador, ou ainda estudante ou técnico. A quantidade de grupos de pesquisa na área da saúde é a mais expressiva, e muitos destes grupos não assinalavam nem a situação de pobreza e nem a educação formal como eixos temáticos de suas linhas de pesquisa.

A maioria dos 98 autores são pesquisadores ou líderes nos grupos de pesquisa, e predominantemente professores nas universidades (ver Quadros 6 e 7). Entretanto, há um número expressivo de profissionais sem identificação ou informação pertinente quanto ao cargo.

Quadro 6 - Autores das produções (artigos, teses, dissertações), por categoria no grupo de pesquisa

\begin{tabular}{|l|c|}
\hline $\begin{array}{l}\text { Categoria do pesquisador no } \\
\text { grupo de pesquisa }\end{array}$ & $\begin{array}{c}\text { Número de autores } \\
\text { pesquisadores }\end{array}$ \\
\hline Líder & 25 \\
\hline Pesquisador & 29 \\
\hline Estudante & 2 \\
\hline Técnico & - \\
\hline Não informado & 42 \\
\hline Total & $\mathbf{9 8}$ \\
\hline
\end{tabular}

Fonte: Base de dados on-line SciELO, BDTDD, Google acadêmico (1999-2009). Elaboração dos autores.

A observação de certa dispersão no que diz respeito à filiação institucional poderia indicar a dificuldade na constituição de linhas de pesquisa com continuidade e aprofundamento teórico. $\mathrm{Na}$ análise dos currículos Lattes dos pesquisadores, também há poucos indícios de constituição de trajetórias acadêmicas sobre o tema, com um mesmo autor ou autora publicando artigo e produzindo 
dissertação e posteriormente tese. Se é prematuro deduzir o futuro da temática com base apenas na análise das produções numa década, é também relevante pensar na progressão acadêmica e na especialização dos jovens estudantes e pesquisadores sobre o tema, visando à consolidação de linhas de pesquisa que permitam o acúmulo dos conhecimentos.

Quadro 7 - Autores das produções (artigos, teses, dissertações), cargo ou função

\begin{tabular}{|l|c|}
\hline Cargo ou função do autor pesquisador & Número de autores pesquisadores \\
\hline Estudante & 4 \\
\hline Gestor público & 1 \\
\hline Professor & 61 \\
\hline Não informado & 32 \\
\hline Total & $\mathbf{9 8}$ \\
\hline
\end{tabular}

Fonte: Base de dados on-line SciELO, BDTDD, Google acadêmico (1999-2009).

Elaboração dos autores.

Conforme mencionado anteriormente, os artigos selecionados assinados por mais de um autor (17 artigos ao total) pertencem em sua maioria à área da saúde. No caso das dissertações e teses, os orientadores e orientadoras exercem um papel fundamental no desenvolvimento da pesquisa; porém, a realização e consequentemente a autoria do trabalho aprovado e publicado é do pós-graduando, sendo considerado um trabalho fundamentalmente solitário.

A frequência com que o mesmo autor foi registrado em diversas produções selecionadas é baixa, havendo uma alta rotatividade de autores interessados na temática. Apenas há duas reiterações de autor entre artigos e dissertações/teses, indicando que o pós-graduando publicou resultados da pesquisa em formato de artigo e/ou que continuou pesquisando sobre o mesmo tema.

Apresentaram-se os dados gerais da pesquisa realizada e refletiu-se sobre quais são as instituições (revistas, universidades), grupos de pesquisa e pesquisadores preocupados com a compreensão da relação entre educação formal e a situação de pobreza. Também foram apontados o desenvolvimento do interesse no tema no decorrer do período analisado e algumas considerações sobre as áreas disciplinares que desenvolvem interesse na temática.

Destarte, respondeu-se ao primeiro objetivo específico desta pesquisa, qual seja: propiciar um levantamento (localização e sistematização) da produção científica elaborada no contexto das ciências sociais e humanas sobre a relação entre a situação de pobreza e a educação formal, considerando apenas as produções publicadas em bases on-line no período compreendido entre 1999 e 2009.

Cabe agora estruturar algumas questões que são consoantes com os objetivos da pesquisa: como foi construída a relação entre situação de pobreza e educação formal pelos/as cientistas das ciências sociais e humanas na última década? É possível elaborar uma tipificação das relações estabelecidas, segundo a 
área de conhecimento da produção considerada? Como são inseridas e analisadas as questões de gênero, raça/cor e classe social nessa relação?

Dessa maneira, adentramos no segundo objetivo específico da pesquisa: estabelecer uma tipologia (comparação e diferenciação) sobre as interpretações realizadas sobre a relação entre situação de pobreza e educação formal por pesquisadores e pesquisadoras incluídos no levantamento.

Uma característica do material analisado é a excessiva pulverização dos assuntos abordados para tratar da relação entre educação formal e situação de pobreza. Os assuntos mais discutidos nas produções analisadas foram, nesta ordem, programas de transferência de renda; exclusão social e desigualdade social; desenvolvimento do país. Em 12 oportunidades houve registro de um único artigo sobre determinado assunto.

\section{Quadro 8 - Assuntos discutidos nas produções selecionadas}

\begin{tabular}{|l|c|}
\hline Assunto & Produç̃̃es \\
\hline Alfabetização & 1 \\
\hline Condição de vida & 2 \\
\hline Desenvolvimento do país & 1 \\
\hline Educação infantil & 2 \\
\hline Educação superior & 2 \\
\hline Estatísticas educacionais & 1 \\
\hline Evasão escolar & 9 \\
\hline Exclusão social e desigualdade social & 2 \\
\hline Formação profissional & 1 \\
\hline Indigência & 2 \\
\hline Juventude & 2 \\
\hline Maternidade na adolescência & 1 \\
\hline Modelo educacional & 1 \\
\hline Mortalidade infantil & 1 \\
\hline Neoliberalismo, globalização & 3 \\
\hline Práticas pedagógicas alternativas (movimentos sociais & 19 \\
\hline e organizações não governamentais - ONGs) & 1 \\
\hline Programa de transferência de renda & 3 \\
\hline Promoção de saúde & 4 \\
\hline Relação Estado-escola & 1 \\
\hline Relação família-escola & 2 \\
\hline Representações sociais & 1 \\
\hline Saúde básica & $\mathbf{6 9}$ \\
\hline Situação de risco & \\
\hline Trabalho infantil & 2 \\
\hline Violação de direitos humanos & 2 \\
\hline Total & 2 \\
\hline & \\
\hline
\end{tabular}

Fonte: Base de dados on-line SciELO, BDTDD, Google acadêmico (1999-2009).

Elaboração dos autores. 
Durante a elaboração das fichas da pesquisa, houve dificuldade com a localização dos conceitos procurados, muitas vezes estando dispersos pelo texto sem uma clara definição. Localizaram-se multiplicidade de expressões e termos por vezes empregados ingenuamente e que remetem a uma pluralidade de conceitos e enfoques teóricos muito distantes da unanimidade.

Como exemplo do que foi citado, a educação formal é interpretada como sinônimo de nível de escolaridade, apontando muitas vezes para a educação infantil. Por vezes, a educação é tida como uma área que deve receber investimentos, sendo esse um meio de mudança da condição social vigente e uma política que deve receber maior atenção do governo por se tratar da formação do cidadão, pois a escola seria o ponto de partida para a construção de um futuro melhor. A situação de pobreza é apontada como uma condição a ser combatida, prevenida. São lembrados termos como "linha da pobreza", que é utilizado para descrever o nível de renda anual com o qual a pessoa não tem condições para sobreviver, estabelecido pelo Banco Mundial como menos de um dólar por dia.

Tal diversidade pode ser entendida como sinal de falta de consenso. Mas também a multiplicidade de descritores e termos pode ser indício de que o campo de reflexão ainda não está constituído, não havendo indicadores claros para identificar o novo recorte. Cabe aqui a sugestão aos autores e autoras, bem como aos organizadores das bases de dados consultadas, que seja oferecida atenção especial aos descritores selecionados para indexação de artigos, teses e dissertações, especialmente por haver a disponibilidade de um rico Thesaurus Brasileiro de Educação (BRASED). ${ }^{2}$

No que diz respeito à relação entre educação formal e situação de pobreza estabelecida nas 69 produções selecionadas, a primeira organização dos dados aponta para a classificação em 13 tipos diferentes de relação (ver Quadro 9). Principalmente, obtiveram presença expressiva as alegações que colocam a educação formal como condição ou como estratégia para a ruptura do círculo da pobreza, ou ainda como mecanismo de manutenção da ordem constituída, resultando na manutenção dos polos opostos em torno do poder da educação formal: antídoto contra os males da pobreza no polo positivo e reprodutora da ordem social estabelecida no polo negativo.

2 Thesaurus é uma palavra latina que significa "tesouro". Foi empregada a partir de 1500 para indicar um acervo ordenado de informações e conhecimentos. O Thesaurus Brasileiro da Educação (BRASED) é um vocabulário controlado que reúne termos e conceitos extraídos de documentos analisados no Centro de Informação Bibliográficas em Educação (CIBEC), relacionados entre si com base em uma estrutura conceitual da área da educação. Esses termos, chamados descritores, são destinados à indexação e à recuperação de informações. Disponível em: <http://www.inep.gov.br/pesquisa/ thesaurus/>. Acesso em: jun. 2011. Nesse vocabulário controlado, foram localizadas apenas quatro expressões vinculadas à situação de pobreza (todas em diferentes níveis): aumento da pobreza, erradicação da pobreza, pobreza, e programa de apoio à educação inicial não formal para populações em situação de pobreza. 
Quadro 9 - Produções selecionadas por tipo de relação estabelecida entre educação formal e situação de pobreza

\begin{tabular}{|l|c|}
\hline Tipo de relação & Número de produções \\
\hline $\begin{array}{l}\text { Escola como antídoto contra os males a que estariam } \\
\text { expostas crianças e jovens pobres ("salvação") }\end{array}$ & 4 \\
\hline Escolaridade como estratégia para atingir o desenvolvimento (do país) & 16 \\
\hline $\begin{array}{l}\text { Escolaridade como condição da mudança na } \\
\text { situação de pobreza (mobilidade social) }\end{array}$ & 9 \\
\hline $\begin{array}{l}\text { Escolaridade como método para romper o } \\
\text { círculo da pobreza (inclusão social) }\end{array}$ & 1 \\
\hline Evasão escolar & 2 \\
\hline $\begin{array}{l}\text { Falta de escolaridade como fator desencadeante } \\
\text { de doenças em situação de pobreza }\end{array}$ & 6 \\
\hline $\begin{array}{l}\text { Falta de escolaridade como causa do desemprego e } \\
\text { subemprego, consequentemente da situação de pobreza }\end{array}$ & 3 \\
\hline Impacto das políticas sociais no sistema escolar & 1 \\
\hline Pobreza como fator explicativo da ausência escolar & 5 \\
\hline Pobreza como fator explicativo do baixo desempenho escolar & 8 \\
\hline $\begin{array}{l}\text { Sistema escolar como porta de entrada para os programas } \\
\text { de renda destinados às famílias pobres }\end{array}$ & 11 \\
\hline $\begin{array}{l}\text { Sistema escolar como estratégia para a manutenção } \\
\text { da ordem social constituída (reprodução) }\end{array}$ & 1 \\
\hline Trabalho infantil & $\mathbf{6 9}$ \\
\hline Total & \\
\hline
\end{tabular}

Fonte: Base de dados on-line SciELO, BDTDD, Google acadêmico (1999-2009).

Elaboração dos autores.

Agora, vejamos algumas reflexões sobre o terceiro e último objetivo específico da pesquisa, as relações de classe, gênero e raça/cor imbricadas na relação entre educação formal e situação de pobreza: analisar as questões de gênero, raça/cor e classe social (identificação e consideração) envolvidas na interpretação da relação entre situação de pobreza e educação formal na produção científica selecionada.

Quadro 10 - Produções selecionadas que fazem referência às categorias específicas de desigualdade (classe, raça/cor, gênero)

\begin{tabular}{|l|c|c|c|c|}
\hline $\begin{array}{l}\text { Número de } \\
\text { produções }\end{array}$ & $\begin{array}{c}\text { Contemplam } \\
\text { classe social }\end{array}$ & $\begin{array}{c}\text { Contemplam } \\
\text { gênero }\end{array}$ & $\begin{array}{c}\text { Contemplam } \\
\text { raça/cor }\end{array}$ & $\begin{array}{c}\text { Não contemplam } \\
\text { especificidades }\end{array}$ \\
\hline Artigos & 17 & 15 & 7 & 12 \\
\hline Dissertações & 11 & 15 & 10 & 2 \\
\hline Teses & 6 & 7 & 9 & 0 \\
\hline Total & 34 & 37 & $\mathbf{2 6}$ & $\mathbf{1 4}$ \\
\hline
\end{tabular}

Fonte: Base de dados on-line SciELO, BDTDD, Google acadêmico (1999-2009).

Elaboração dos autores. 
Das 69 produções analisadas, 55 produções referem-se aos temas, trazendo em seus escritos as questões gênero, classe social e/ou raça/cor, obedecendo essa respectiva ordem dentro do seu conteúdo analítico. Vale observar que a maioria das produções faz referência a uma ou mais especificidades de desigualdade e contempla gênero, classe social e raça/cor, nessa ordem respectivamente.

Apenas 14 não fazem referência alguma a essas três categorias, indicando que estas não são consideradas elementos importantes da situação de pobreza ou das condições da educação formal. Com relação aos conceitos de classe social, raça/ cor e gênero, registrou-se a mesma diversidade quanto à conceituação utilizada para definir educação formal e situação de pobreza.

O conceito de classe social pode ser interpretado de duas formas: como um estrato social, de consciência e sociabilidade próprias, sendo sinônimo de camada social e entendido como um conceito descritivo, ou pode ser interpretado como uma estrutura social, que regula a ação coletiva na sociedade capitalista, condicionando a sociabilidade própria à modernidade e ao capitalismo universais, sendo nesse caso um conceito explicativo.

Na visão marxista, com a Revolução Industrial surgiram duas classes sociais como um produto histórico e da sociedade capitalista. Nas produções localizadas e analisadas, são apontados os termos "classes trabalhadoras" e "classes operárias", porém são poucos os autores que recorrem a Marx para explicar as relações de trabalho que estão envolvidas nesse contexto de separação das classes por condição econômica. A fórmula encontrada em grande parte dos artigos selecionados e que possibilitaria um direcionamento da construção do pensamento sobre a perspectiva de classe seria a estratificação social, segundo a qual a sociedade apresenta-se dividida em classes em virtude da sua condição econômica. Esses artigos recorrem a conceitos preestabelecidos e amplamente utilizados, como a linha da pobreza e a linha da indigência. Também é observada a abordagem de classe como uma questão de oportunidades de vida e das possibilidades de crescimento social, em que a ocupação seria um indicador de classe e a posição social poderia ser alcançada conforme as possibilidades existentes, permitindo uma mobilidade, podendo ser ascendente ou descendente.

Em relação à temática de gênero, observaram-se três categorias-chave utilizadas sucesivamente pelas acadêmicas feministas: sexo, gênero e sexualidade. As concepções baseadas no sexo encontram-se diretamente relacionadas com a observação de características decorrentes da natureza e da biologia, da condição anatômico-fisiológica dos indivíduos, dividindo-os ou classificando-os em machos e fêmeas, sem abrir o espaço ainda para a discussão da construção cultural do feminino e do masculino.

O conceito de relações de gênero, difundido amplamente por Scott (1990), refere-se por sua vez à construção cultural ou interpretação cultural do biológico ou natural e ao estabelecimento das suas relações recíprocas e internas, porém também se limita a duas possibilidades: o gênero masculino e o gênero feminino. A última categoria é a que apresenta maior número de discussões, utilizando como ponto de 
reflexão a questão da sexualidade. Discutem-se a heteronormatividade e as novas expressões das relações sociais que as concepções de sexo e posteriormente de gênero não apontavam ou problematizavam.

Nas produções selecionadas, a temática de gênero é abordada de maneira superficial, sendo apresentada apenas como um recorte, em especial aqueles que são associados a questões de escolaridade e mercado de trabalho, ou escolaridade e saúde. Evidenciaram-se discussões nas quais o tema gênero associa-se ao impacto da gravidez na adolescência nos setores de baixa renda, normalmente significando a interrupção da escolarização com o nascimento do primero filho (a não continuidade dos estudos significará menor qualificação e, portanto, menores chances de competir num mercado de trabalho cada vez mais exigente e com menos ofertas, implicando normalmente a inserção em tarefas informais com baixa remuneração). Também foram registradas relações entre a escolaridade da mãe e a mortalidade infantil precoce.

Na conceituação da temática racial, segundo Guimarães (2002, p. 50), o conceito raça não se associa a nenhuma realidade natural, mas sim a uma forma de classificação social, que é embasada tanto por atitudes negativas perante determinados grupos sociais, como por uma noção específica de natureza. Pode-se então dizer que raça é uma construção social.

Raça não é apenas uma categoria política necessária para organizar a resistência ao racismo no Brasil, mas é também categoria analítica indispensável: a única que revela que as discriminações e desigualdades que a noção brasileira de "cor" enseja são efetivamente raciais e não apenas de "classe".

Nas produções selecionadas, a questão racial é apenas mencionada superficialmente, sendo apresentada apenas como um recorte em indicadores estatísticos, em especial aqueles que são associados a questões de escolaridade e mercado de trabalho. Nesse contexto, chama a atenção um ensaio que busca discutir a política de identidade que está sendo proposta no Brasil com o fim de combater o racismo, pretendendo também refletir sobre o significado da racialização das políticas públicas e dos nossos costumes. Das três categorias analisadas, a questão raça/cor constitui a mais frágil quanto aos estudos desenvolvidos em torno da tematização da relação entre educação formal e situação de pobreza.

\section{UM CAMPO EM (RE)DEFINIÇÃO}

Utilizando as classificações da pedagogia desenvolvidas por Saviani (2005), podem ser identificadas duas grandes maneiras de relacionar a educação formal e a situação de pobreza. De um lado, a educação formal é analisada de maneira positiva, como motor para a ruptura da desigualdade social, propiciando a mobilidade social da população pauperizada e promovendo uma cidadania crítica (otimismo pedagógico próprio da concepção pedagógica produtivista, revigorada no contexto neoliberal). De outro lado, numa visão negativa, a educação formal pode ser consi- 
derada reforçadora da desigualdade social na sociedade capitalista, uma vez que o sistema educacional se centra na distribuição de certificações educacionais, exigindo que a população historicamente desfavorecida supra uniformemente as exigências de uma instituição escolar moldada segundo parâmetros que the são alheios (pessimismo pedagógico próprio das pedagogias críticas).

$\mathrm{Na}$ tentativa de fugir à polarização anteriormente mencionada entre as visões otimistas e pessimistas da educação formal, autores mais recentes afirmam que a relação entre a situação de pobreza e a educação formal é muito mais complexa e não se expressa de forma linear. Assim, a educação formal é visualizada como parte de uma complexa trama que na tessitura da relação Estado-sociedade reúne elementos não apenas cognitivos ou propriamente pedagógicos, mas elementos econômicos (distribuição de bens simbólicos que operam posteriormente como chaves para a inserção no mercado de trabalho capitalista e para o consumo dos bens materiais), elementos culturais (reconhecimento dos bens simbólicos que merecem ser conservados, distribuídos e certificados) e elementos políticos (estabelecimento de mecanismos de exclusão total e de inclusão excludente, seleção "meritocrática" de lideranças).

Levando em consideração essa quádrupla perspectiva (educativa, econômica, cultural e política), pode ser de utilidade analisar os mecanismos específicos de discriminação que atuam na relação entre situação de pobreza e educação formal, os quais questionam a "normalidade" dos parâmetros estabelecidos.

Os mecanismos de discriminação com base no gênero, na raça/cor e na classe social podem contribuir para o estabelecimento de análises que não se emaranhem na tensão entre os aspectos positivos e os negativos da relação entre educação formal e situação de pobreza. Também podem explicar por que a expansão do sistema escolar não resultou nas mudanças almejadas, por que a suposta igualdade de oportunidades não leva a uma igualdade de resultados, por que a educação formal é condição para o emprego e também para a integração social, entre outros aspectos do enigma. Precisamos de uma visão mais complexa da relação do sistema educacional com as desigualdades sociais decorrentes da classe social, mas também, da mesma maneira, do gênero e da raça/cor.

Especialmente promissoras parecem ser as conceituações que permitem captar os circuitos educacionais segmentados (níveis do sistema) e diversificados (tipos de estudo) com base na classe social e na raça/cor dos frequentadores, combinadas com o estudo das trajetórias educacionais diferenciadas em virtude do gênero do corpo discente. No primeiro caso, está se falando de frequentar instituições distintas ou atingir patamares de escolaridade diferentes em razão da origem racial e de classe. No segundo caso, está se afirmando que é possível estudar coisas diferentes e transitar entre o sistema educacional e o mercado de trabalho de maneiras até opostas quando se é membro de um ou de outro gênero. A almejada mobilidade social parece depender menos da escolaridade e mais dos tipos de circuitos e trajetórias educacionais.

Se nos artigos e em outras produções selecionadas para esta pesquisa encontrou-se um número significativo de indicações da relação entre educação formal e mercado de trabalho, e entre educação formal e acesso aos serviços de saúde, seria importante correlacionar esses dados com a participação nos tipos de circuitos e trajetórias educacionais. 
Como Apple (2005) ensina e reitera sistematicamente, ao se propor argumentos contra o reducionismo econômico, é necessário tomar alguns cuidados para não exagerar. Efetivamente, as escolas e as práticas educacionais sofrem, nos tempos atuais, a constante pressão para se adaptarem às necessidades econômicas determinadas pelos setores dominantes, orientadas para o aumento constante da produtividade (e do consumo). Entretanto, ainda que aceitemos a determinação em última instância da esfera econômica, muitos fenômenos educacionais não são explicáveis sem uma análise que incorpore as questões de gênero e raça/cor. Por exemplo, a análise exclusivamente econômica de custo-benefício não consegue explicar por que as mulheres obtêm menos retorno do investimento realizado em estudos superiores ou conseguem menor mobilidade social com base nos anos de escolaridade do que os homens, especialmente, mas não unicamente, as mulheres negras.

Outro aspecto interessante na renovação do pensamento em torno da relação entre educação formal e situação de pobreza remete ao próprio conceito de educação formal e de escola. A educação formal se configura como organização sistêmica que depende de uma diretriz educacional centralizada com base em legislações, currículo e de estruturas de monitoramento e fiscalização nacionais. No caso do Brasil, o órgão responsável por realizar tais tarefas é o Ministério da Educação (MEC). A execução da educação formal se dá nas escolas e universidades, espaços educacionais marcados por regularidade, hierarquia e sequencialidade (Gadotti, 2005).

Entretanto, a educação formal não é uniforme, não é homogênea, ainda que seja pautada por regularidades advindas das políticas educacionais. As escolas têm diferentes sentidos e utilidades para diferentes populações, incentivando os indivíduos a procurarem-na como elevador social (indispensável para a formação da força de trabalho, propiciando maior adaptabilidade às mudanças no processo de trabalho) ou mesmo um passaporte para o futuro (indispensável para a integração social, atenuando as disparidades sociais e contendo as possibilidades de conflito) (Oliveira, 2000).

Esse é o núcleo fundamental da pedagogia da exclusão. Saviani (2008, p. 182) define a pedagogia da exclusão como:

A ordem econômica atual, denominada pós-fordista e pós-keinesiana, pressupõe a exclusão, categoria que comparece duplamente: ela é pressuposta, num primeiro sentido, na medida em que se admite, preliminarmente, que na ordem econômica atual não há lugar para todos. Portanto, boa parte daqueles que atingem a idade para ingressar na PEA [População Economicamente Ativa] nela sequer chega a entrar. Num segundo sentido, a exclusão é pressuposta porque, incorporando crescentemente a automação no processo produtivo, a ordem econômica atual dispensa, também de forma crescente, mão de obra. [...] Configura-se, então, nesse contexto, uma verdadeira "pedagogia da exclusão". Trata-se de preparar os indivíduos para, mediante sucessivos cursos dos mais diferentes tipos, tornarem-se cada vez mais empregáveis, visando a escapar da condição de excluídos. E, caso não o consigam, a pedagogia da exclusão lhes terá ensinado a introjetar a responsabilidade por essa condição. 
As escolas públicas cumprem um papel central de agência estatal, sendo muitas vezes a única representação do poder público em determinados espaços geográficos (Oliveira, 2003). Foram estabelecidas historicamente articulações profícuas entre as políticas educacionais e outras políticas, especialmente as de saúde e as de assistência, pois nas escolas estavam e estão as crianças.

As escolas tornaram-se porta de entrada para a diversidade de ações e programas, como vacinação, alimentação, renda. No espaço físico da educação formal, outras funções e tarefas foram e são processadas, transformando o espaço educacional em muito mais do que um espaço unicamente educativo. Passa-se a um espaço escolar no qual são realizadas múltiplas maneiras de atenção às necessidades da população mais pobre, como: alimentação e nutrição, saúde e higiene, vestuário, renda, entre outras (Algebaile, 2009).

Algumas das ações e programas para atendimento dessas necessidades sociais, como vacinação, merenda escolar, material escolar, uniforme etc., são aplicadas de forma genérica ou universal. Outros, decorrentes da política de assistência social, são profundamente focalizadas, como o Bolsa família e outros programas semelhantes de transferência de renda executados no espaço escolar ou com condicionalidade educacionais.

No caso das ações focalizadas, destinadas à minoria mais pobre, porém com certo grau de articulação institucional, a relação da educação com a assistência social é clara. $\mathrm{O}$ pano de fundo é a ideia de compensar um suposto déficit familiar que não permitiria à criança atingir o rendimento escolar médio esperado (reforço escolar, atividades socioeducativas) e evitar que a criança seja pressionada, por exemplo, a gerar uma renda por meio do trabalho, consequentemente abandonando a escola.

Segundo Connell (apud Gentili, 2002) os programas compensatórios dessa natureza possuem três pressupostos problemáticos: a) que o problema somente está relacionado com essa minoria afetada; b) que o pobre é diferente da maioria (cultural e psicologicamente); e c) que a solução para o problema é técnica.

Os alunos pobres no Brasil são a maioria: 17 milhões de beneficiários do Programa Bolsa família em um contingente de 34 milhões, e a escola não os enxerga! A complexa trama da qual se falou é ignorada, pois o foco do programa que resolveria os problemas identificados está na compensação de déficits que são atribuídos aos indivíduos e às suas famílias, nunca ao sistema escolar e muito menos ao sistema capitalista como um todo. Não há impactos significativos sobre o currículo no intuito de rever a maneira em que foi construído e a que interesses de classe atende, ou ainda visando a uma espécie de "justiça curricular". ${ }^{3}$

Se exige das famílias a condicionalidade da frequência escolar dos filhos para perceber a renda dos programas de transferência como o Programa Bolsa família,

3 É necessário reconhecer que as pressões realizadas pelos movimentos feminista e negro por legitimação de conteúdos foram mais bem-sucedidas, decorrendo delas a incorporação de saberes e questionamentos às tradicionais visões masculinas e brancas. 
insinuando que as famílias na verdade desejariam retirar seus filhos da escola e que são as pequenas rendas do Estado que as persuadem para não o fazer, contradizendo destarte todas as pesquisas que comprovam exatamente o contrário: o grande valor que as classes mais desfavorecidas outorgam à educação formal (ver a respeito, entre outros relatos de pesquisa, Naiff; Sá; Naiff, 2008).

As famílias beneficiárias pouco podem exercer o direito ao controle social na formulação e na avaliação dessas políticas compensatórias, em virtude justamente da sua condição de vulnerabilidade extrema. Mais do que condicionalidade ou ameaça de desligamento da família do programa por descumprimento das exigências, o que deve ser ressaltado é o direito de todo cidadão a ter acesso ao trabalho e aos programas sociais que garantam uma vida com dignidade. As condicionalidades deveriam ser impostas ao Estado em seus três níveis (federal, estadual e municipal) e não às famílias, pois é o Estado que não cumpre com os deveres fixados constitucionalmente com relação ao direito à educação (Silva, 2007).

Outro problema da relação entre educação formal e situação de pobreza decorre da nula participação dos professores na formulação dos programas assistenciais veiculados no âmbito escolar, bem como da nula participação dos assistentes sociais nas unidades de ensino. As intersecções entre as políticas assistenciais (de caráter focalizado nos segmentos mais pobres da sociedade) e as políticas educacionais (universalistas e em princípio abertas para todos) denunciam uma convivência pouco clara e uma tensão permanente entre as diferentes lógicas. Mesmo atendendo a faixas etárias incluídas na obrigatoriedade escolar dentro do ensino público, os programas assistenciais são paralelos às redes escolares. Alguns programas assistenciais foram absorvidos e universalizados pelas escolas públicas - por exemplo, a merenda escolar -, incorporados ao seu funcionamento desde o planejamento e financiamento até as suas práticas. Outros programas, como o Bolsa escola/família, são introduzidos no seio escolar e provocam diferenciações entre os alunos (Campos, 2003).

São indícios preocupantes os que se depreendem de alguns estudos recentes nas escolas públicas que atendem populações vulneráveis (Guimarães-Iosif, 2009). As professoras ${ }^{4}$ consideram que a escola deve se preocupar exclusivamente com a aprendizagem e não com questões relacionadas à situação de pobreza ou à desigualdade social. E ainda salientam que a incorporação de programas de transferência de renda no cotidiano escolar está fazendo com que alunos e pais não vejam mais a escola como espaço de aprendizagem e sim como uma fonte de recursos financeiros, um elo entre a situação de pobreza e o aluno/família. Como trabalhar essa relação, como aproximar professores e assistentes sociais para atender conjuntamente aos direitos sociais da população?

4 Optou-se por usar o gênero gramatical feminino para definir a categoria profissional docente, visto que em sua maioria (quase 90\%) são mulheres, segundo censo de 2009 do INEP: as professoras no ensino fundamental no Brasil são 655.097, e os professores são apenas 66.416. 
Também preocupa a constatação das enormes dificuldades que enfrenta a infância pobre para frequentar a escola (Freitas, 2006). Com alunos em situações de severa pobreza, a escola passa por um processo de transformação na maneira em que é "consumida" pelos alunos, de tal maneira que por vezes a própria forma de ser do escolar está em jogo. Os alunos muito pobres constituem um desafio para as professoras que trabalham em inacreditáveis condições de precariedade na maioria das escolas públicas periféricas, muitas vezes sendo esses alunos “tolerados" - e não verdadeiramente incluídos - por falta de opções para desenvolver outro tipo de trabalho pedagógico.

A ampliação da educação básica (especialmente o ensino fundamental) está relacionada com a utilização das escolas públicas para a intervenção do Estado, visando promover a empregabilidade futura dos novos cidadãos, ou, quando essa não é uma alternativa possível tendo em vista a sociedade dual, visando compensar situações focalizadas de injustiça econômica que poderiam levar à desintegração social. Nessa segunda situação, trata-se paradoxalmente da expansão educacional por meio da extrema negação da educação pública e de qualidade para as maiorias, pois a educação formal para os pobres foi transformada em condição de acesso a uma renda mínima.

\section{PARA (RE)VIGORAR O CAMPO}

Em consulta realizada no site da Associação Brasileira de Ensino e Pesquisa em Serviço Social (ABEPSS) e da Associação Nacional de Pós-Graduação e Pesquisa em Educação (ANPEd), ${ }^{5}$ percebeu-se que não há grupos temáticos constituídos para tratar a temática da relação entre educação formal e situação de pobreza. A consulta realizada nas produções que refletem o estado atual de desenvolvimento das pesquisas e programas de pós-graduação em educação e serviço social, as duas grandes áreas diretamente envolvidas nessa relação, indica que não há uma preocupação significativa sobre a temática (ver, por exemplo, Santos; Azevedo, 2009 e Temporalis, 2007). Em segundo lugar, é necessário destacar que há uma grande dispersão de assuntos abordados. Essa seria talvez a maior dificuldade a ser enfrentada para a constituição de um campo específico de estudos em torno da relação entre situação de pobreza e educação formal.

Em que pese a diversidade de assuntos abordados, algumas lacunas temáticas foram detectadas pela pesquisa sobre a temática e preocupam especialmente os autores em virtude de estarem inseridos no Departamento de Serviço Social da Universidade de Brasília. A saber:

- Incorporação nas escolas e na educação formal de adolescentes em liberdade assistida;

- Incorporação nas escolas de crianças e adolescentes abrigados;

$\overline{5 \text { Acesso em: } 11}$ fev. 2010. 
- Em ambos os grupos, a situação de pobreza está presente de maneira contundente;

- Ausência de tratamento da temática da pobreza nos projetos político-pedagógicos;

- Conceitualização da situação de pobreza na formação dos professores.

A constituição de um campo específico de reflexão em torno da relação entre situação de pobreza e educação formal urge, pois, sem ele, como pensar uma pedagogia contra-hegemônica? Como desenvolver os elementos que deveriam incluir uma visão renovadora da pedagogia, no intuito de construir uma verdadeira pedagogia da inclusão?

Existe um debate em torno do ensino infantil, referido ao tipo de política setorial na qual estaria incluído. Trata-se de cuidar ou de educar as pequenas crianças? Essa questão apareceu com força no processo de transferência das creches do Ministério do Desenvolvimento Social e Combate à Fome (MDS) ao MEC e, embora camuflada, também permeia o ensino fundamental.

$\mathrm{O}$ fato de não serem tão dependentes da presença de um adulto para a satisfação de suas necessidades humanas ${ }^{6}$ não torna as crianças maiores de 6 anos seres que possam prescindir de todo e qualquer cuidado. Na verdade, todos seres humanos precisam de cuidados de diferentes naturezas, e até os adultos deveriam ser observados por esse ponto de vista no que se refere às suas necessidades humanas, inclusive no ambiente de trabalho. Nunca é demais recordar as lutas pela jornada de trabalho, pausa para almoço, dispor de uma cadeira para sentar-se etc. Trata-se de humanizar os espaços e os ambientes nos quais desenvolvemos grande parte de nossa vida.

Então, não é porque as escolas públicas atendem a crianças "carentes" ou vulneráveis que no espaço escolar deve ser garantida a merenda, a vacina, o uniforme, o material escolar, entre outros elementos. Não é porque há necessidade de compensar um "déficit" do lar que ações e programas são implementados para ampliar e melhorar o trabalho pedagógico das escolas e dos professores. Mas sim porque todas as crianças são protegidas legalmente tanto pela Constituição Federal como pela Lei de Diretrizes e Bases (LDB) e pelo Estatuto da Criança e do Adolescente (ECA).

6 Uma definição superficial de pobreza a entende como a privação dos mínimos sociais, ou seja, o mínimo para a subsistência do ser humano. Ao se aprofundar no debate, percebe-se que existe uma diferença entre mínimo e básico no que diz respeito à provisão das necessidades humanas. "Ỏ básico expressa algo fundamental, principal, primordial” ao passo que "o mínimo pressupõe a supressão ou cortes de atendimentos" (Pereira, 2008, p. 26). Para Pereira (2008), existe uma questão central na discussão sobre necessidades humanas: a de conceituá-las de forma objetiva e universal. Todo ser humano, em qualquer tempo histórico, em todos os lugares, nas mais diversas culturas, tem necessidades básicas comuns, que se diferenciam de desejos e preferências pessoais e culturais. Além disso, a satisfação dessas necessidades é variável dependendo do tempo histórico, do local e da cultura, mas as necessidades não são passíveis de variação. 
Os direitos estabelecidos nesses documentos acompanham as crianças em todos os espaços públicos e privados onde estão ou transitam, outorgando direito à saúde, alimentação, educação, segurança, lazer etc. A proteção é à totalidade dos direitos, na totalidade dos espaços onde elas estão, na totalidade do tempo: na escola, na comunidade, nos clubes etc.

Não é por ser a escola pública uma espécie de "estado de pobres", conforme definição de Algebaile (2009), mas toda escola deve garantir a totalidade dos direitos enquanto as crianças estão no seu espaço, no tempo escolar.

Não significa isso que os professores devam tomar conta de todas as áreas e programas, por isso é preciso ter equipes multidisciplinares em todas as escolas. Não significa isso que os professores sejam os únicos responsáveis por todas as áreas, dimensões e programas, por isso é preciso ter equipes multidisciplinares em todas as escolas. A criança é uma só, não é ora educando, ora filho, ora doente, ora vulnerável.

O pedagógico deve ser o propósito principal da escola, concordando-se plenamente, porém não o único. Direito estruturante, proeminente no espaço escolar, porém não excludente dos demais direitos a serem garantidos a todas as crianças em todos os momentos. Ele deve ser o grande organizador das atividades de ensino no espaço e no tempo escolar, mas os demais direitos não podem ser descuidados ou negligenciados, pois, caso contrário, o processo educativo não acontece, não tem lugar, acontece de maneira parcial e às vezes até contraproducente.

Atribuir unicamente à expansão da escolaridade a expectativa de melhorar a justiça social no país é ilusório, e nos encaminha para uma espécie de cilada (Gentili, 2007). O problema não é descobrir tecnicamente como colocar mais crianças na escola, ou como impedir que estanquem num determinado ano do ensino fundamental. O problema também não é como levar renda às famílias independentemente da aprendizagem e dos direitos culturais das crianças. O problema é qualitativo e ético, mais do que quantitativo ou técnico.

Precisamos entender a escola pública na sua complexa trama atual, envolvendo questões econômicas, políticas, culturais e educacionais. O reconhecimento das múltiplas funções e expectativas colocadas na escola pública deveria alentar um trabalho interdisciplinar (educação e serviço social entre as principais) e um olhar dos diversos saberes situados (professoras, gestoras, estudantes, pais, funcionários, entre outros), para que se recupere o sentido do direito à educação como direito social, para além da denúncia indignada da lamentável situação. A educação formal não pode o todo, não é condição suficiente para a mudança radical da sociedade, mas é condição necessária para o exercício da cidadania.

\section{REFERÊNCIAS}

Algebaile, Eveline. Escola pública e pobreza no Brasil. A ampliação para menos. Rio de Janeiro: Lamparinha/FAPERJ, 2009.

Apple, Michael W. Para além da lógica do mercado: compreendendo e opondo-se ao neoliberalismo. Rio de Janeiro: DP\&A Editora, 2005. 
Brasil. Ministério da Educação. INEP. Censo Escolar 2009. Brasília, 2009.

CAmpos, Maria Malta. Educação e políticas de combate à pobreza. Revista Brasileira de Educação, Rio de Janeiro, ANPEd; Campinas, Autores Associados, n. 24, p. 183-191, set./dez.2003. Disponível em: <http://dx.doi.org/10.1590/S1413-24782003000300013. Acesso em: jun. 2011.

Connell, Robert. Pobreza e educação. In: Gentili, Pablo (Org.). Pedagogia da exclusão: crítica ao neoliberalismo em educação. 10. ed. Petrópolis: Vozes, 2002. p. 11-42.

Freitas, Marcos Cezar de (Org.). Desigualdade social e diversidade cultural na infância e na juventude. São Paulo: Cortez Editora, 2006.

Gadotti, Moacyr. A questão da educação formal/não formal. In: Institut Internacional des Droits de L'Enfant (IDE). Direito à l'éducation. Sion, p. 1-11, 18-22 oct. 2005.

Gentili, Pablo. Desencanto y utopía. La educación en el laberinto de los nuevos tiempos. Rosario: Homosapiens Ediciones, 2007.

. (Org.). Pedagogia da exclusão: crítica ao neoliberalismo em educacão. 10. ed. Petrópolis: Vozes, 2002.

Guimarães, Antônio Sérgio. Classes, raças e democracia. São Paulo: Fundação de Apoio à Universidade de São Paulo/Editora 34, 2002.

Guimarães-Iosif, Ranilce. Educação, pobreza e desigualdade no Brasil. Brasília: Liber Livro, 2009.

Naiff, Luciene Alvez Miguez; SÁ, Celso Pereira de; Naiff, Denis Giovani Monteiro. Preciso estudar para ser alguém: memória e representações sociais da educação escolar. Paidéia, Ribeirão Preto, Universidade de São Paulo, Faculdade de Filosofia Ciências e Letras de Ribeirão Preto, v. 18, n. 39, p. 125-138, 2008.

Oliveira, Dalila Andrade. Educação básica. Gestão do trabalho e da pobreza. Petrópolis: Editora Vozes, 2000.

. (Org.). Reformas educacionais na América Latina e os trabalhadores docentes. Belo Horizonte: Autêntica, 2003.

Pereira, Potyara Amazoneida Pereira. Necessidades humanas: subsídios à crítica dos mínimos sociais. 5. ed. São Paulo: Cortez, 2008.

Santos, Ana Lúcia Felix dos; Azevedo, Janete Maria Lins de. A pós-graduação no Brasil, a pesquisa em educação e os estudos sobre a política educacional: os contornos da constituição de um campo acadêmico. Revista Brasileira de Educação, Rio de Janeiro, ANPEd; Campinas, Autores Associados, v. 14, n. 42, p. 534-550, set./dez. 2009.

Saviani, Dermeval. A pedagogia no Brasil: história e teoria. Campinas: Autores Associados, 2008. .Educação brasileira: estrutura e sistema. 9. ed. Campinas: Autores Associados, 2005. 
Scotт, Joan. Gênero: uma categoria útil de análise histórica. Educação e Realidade, Porto Alegre, Faculdade de Educação/UFRGS, v. 15, n. 2, p. 71-99, jul./dez., 1990.

Sen, Amartya. Desenvolvimento como liberdade. São Paulo: Companhia das Letras, 2000. Silva, Ozanira da Silva. O Bolsa família: problematizando questões centrais na política de transferência de renda no Brasil. Ciência É Saúde Coletiva, Manguinhos, Associação Brasileira de Pós-Graduação em Saúde Coletiva (ABRASCO), v. 12, n. 6, p. 1.429$-1.439,2007$.

TEMPORALIS. Revista da Associação Brasileira de Ensino e Pesquisa em Serviço Social (ABEPSS), ano VII, n. 14, jul./dez. 2007.

Yannoulas, Silvia Cristina; Monteiro, Kaline Ferreira; Assis, Samuel Gabriel. Construindo uma tipologia da relação entre a pobreza e a educação formal na literatura cientifica recente (1999-2009): questões de gênero, raça e classe social. Relatório de progresso do projeto de pesquisa. Brasília: TEDis/SER/UnB, fev. 2010.

\section{SOBRE OS AUTORES}

Silvia Cristina Yannoulas é doutora em sociologia pela Universidade de Bueno Aires. Professora adjunta da Universidade de Brasília (UnB). E-mail: silviayannoulas@unb.br

Samuel Gabriel Assis é graduado em serviço social pela Universidade de Brasília (UnB). Assistente social do Instituto Federal de Brasília (IFB). E-mail: samuelgassis@yahoo.com.br

Kaline Monteiro Ferreira é graduada em serviço social pela Universidade de Brasília (UnB). E-mail: kalinemonteiro@yahoo.com.br 
SILVIA CRISTINA YANNOULAS, SAMUEL GABRIEL ASSIS E KALINE MONTEIRO FERREIRA

\section{Educação e pobreza: limiares de um campo em (re)definição}

$\mathrm{O}$ artigo discute a produção acadêmica contemporânea brasileira sobre a relação entre educação formal e situação de pobreza, a partir da procura em três fontes: Biblioteca Digital Brasileira de Teses e Dissertações (BDTD), a Scientific Electronic Library OnLine (SciELO) e o Google Acadêmico. Também foram analisados dados sobre os autores, utilizando a Plataforma Lattes e o Diretório de Grupos de Pesquisa do Conselho Nacional de Desenvolvimento Científico e Tecnológico (CNPq). Os objetivos da pesquisa foram: a) propiciar um levantamento (localização e sistematização) da produção científica 
elaborada no contexto das ciências sociais e humanas sobre a relação entre situação de pobreza e educação formal; b) estabelecer uma tipologia (comparação e diferenciação) das formas que assume a mencionada relação na visão dos pesquisadores e pesquisadoras; e c) analisar as questões de gênero, raça/cor e classe social (identificação e consideração) envolvidas na relação entre a pobreza e a educação formal nessa produção científica. Os resultados mostram que há um interesse crescente na relação entre educação formal e situação de pobreza, com maior concentração das publicações nas áreas disciplinares de educação, economia, saúde e serviço social. A frequência com que o mesmo autor ou um mesmo grupo foi registrado é baixa, indicando uma alta rotatividade de interessados na temática. Os assuntos mais discutidos foram "Bolsa escola, Bolsa familia ou outro programa de transferência de renda" "exclusão social e desigualdade social”. Foram encontradas 13 maneiras diferentes de se relacionar a educação e a pobreza, sendo prediminantemente: a "escolaridade como condição da mudança na situação de pobreza".

Palavras-chave: educação formal; situação de pobreza; gênero; classe socioeconômico; raça/cor.

\section{Education and poverty: thresholds of a field in (re)definition}

This article discusses the contemporary Brazilian academic production on the relation between formal education and poverty, using three sources: the Brazilian Digital Library of Thesis and Dissertations (BDTD), the Scientific Eletronic Library OnLine (SciELO) and the Google Scholar. Data on authors were also analyzed using Lattes Platform and the Research Group Directory of the National Council of Scientific and Technological Development (CNPq). The research objectives were: a) to provide a survey (location and systematization) of the scientific production of social sciences and humanities on the relationship between poverty and formal education; b) to establish a typology (comparison and differentiation) of the forms such relation has in the views of researchers and research subjects, and c) to examine the issues of gender, race and social class (identification and consideration) involved in the relation between poverty and formal education in such scientific production. Results have shown that there is an increasing interest in the relation between formal education and poverty, with higher concentration of publications in the fields of Education, Economics, Health and Social Work. The registration frequency of a given author or group was low, indicating a strong turnover of the people interested in the theme. The most discussed subjects were "school allowance, family allowance or other income transfer programs", and also "social exclusion and social inequality". There were 13 different ways of relating education and poverty, and the most present was "Education as a condition of change in poverty situation".

Keywords: formal education; poverty; gender; socio-economic class; race/skin color.

\section{Educación y pobreza: umbrales de un campo en (re)definición}

El artículo discute la producción académica contemporánea brasileña sobre la relación entre educación formal y situación de pobreza, a partir de la búsqueda realizada en tres fuentes de datos: Biblioteca Digital Brasileira de Teses e Dissertaçôes (BDTD), Scientific Eletronic Library OnLine (SciELO) y Google Académico. También se han analizado datos sobre los 
autores de dicha producción, obtenidos vía Plataforma Lattes y Directorio de Grupos de Investigación del Conselho Nacional de Desenvolvimento Cientifico e Tecnológico (CNPq). Los objetivos de la investigación son: a) propiciar la localización y sistematización de la producción cientifica elaborada en el contexto de las ciencias sociales y bumanas sobre la relación entre pobreza y educación formal; b) establecer una tipología (comparación y diferenciación) sobre las maneras en que los investigadores e investigadoras interpretan esa relación; y c) analizar las cuestiones de género, raza y clase social (identificación y consideración) incluidas en dicha relación. Los resultados muestran que hay un interés creciente en la relación entre la educación formal y la situación de pobreza, con mayor concentración de publicaciones en áreas disciplinarias como Educación, Economía, Salud y Trabajo Social. La frecuencia con que el mismo autor o el mismo grupo de investigación fue encontrado es baja, indicando una alta rotación de interesados en la temática. Los asuntos más abordados fueron "beca escuela, beca familia u otro programa de transferencia de ingresos", y "exclusión social y desigualdad social". Se han encontrado 13 maneras diferentes de relacionar la educación y la pobreza, y la predominante es "escolaridad como condición del cambio en la situación de pobreza".

Palabras clave: educación formal; situación de pobreza; género; clase socioeconómica; razalcolor. 